\title{
Negative Area Compressibility in Oxalic Acid Dihydrate
}

\author{
Francisco Colmenero*
}

Instituto de Estructura de la Materia, CSIC. C/ Serrano, 113. 28006 Madrid, Spain

\begin{abstract}
The main purpose of this communication is to show that the oxalic acid dihydrate exhibits the important phenomenon of negative area compressibility (NAC) when submitted to negative isotropic pressures. The $a$ and $c$ lattice parameters of the oxalic acid dihydrate increase under the effect of increasing external pressures within the ranges from $-1.17 \mathrm{GPa}$ to $-0.12 \mathrm{GPa}$ and from $-1.17 \mathrm{GPa}$ to $-0.51 \mathrm{GPa}$, respectively. The largest magnitude of the compressibility along $a$ direction is found at $\mathrm{P}=-0.83 \mathrm{GPa}$ $\left(k_{a}=-166.21 \mathrm{TPa}^{-1}\right)$. The magnitude of the negative compressibility along the $a$ crystallographic direction in the oxalic acid dihydrate is one the largest found up to date.
\end{abstract}

Keywords: Oxalic acid dihydrate; Negative area compressibility; Periodic density functional theory.

*E-mail: francisco.colmenero@iem.cfmac.csic.es; Orcid: https://orcid.org/0000-0003-3418-0735 


\section{Introduction}

The bulk modulus (or its inverse, the compressibility) is a mechanical property which must be strictly positive for solid materials which are thermodynamically and mechanically stable [1-6]. A material submitted to a hydrostatic (isotropic) pressure cannot increase its volume, unless it is unstable. Negative linear compressibility (NLC) is not related to unstable materials and may refer [1-6] to: $(i)$ the positive variation of the volume when the material is submitted to a uniform compression directed along a given direction, and (ii) the increase of one or two single directions of the unit cell of a material under the application of a hydrostatic pressure. In the first case the directional derivative of the volume with respect to pressure is negative. In the second case, the volume does not increase and the positive variation of the parameters in some directions is compensated by a larger negative variation of the parameters in the remaining directions. When the increase concerns to a single lattice parameter, the term NLC is used. However, in the case that two lattice parameters increase under the action of an isotropic compressive pressure, the observed effect is denominated negative area compressibility (NAC). Negative area compressibility is much more infrequent than negative linear compressibility. The number of known NAC materials is very small and all of them simultaneously also exhibit negative thermal expansion. Some examples are $\mathrm{NaV}_{2} \mathrm{O}_{5}$ [7], $\mathrm{TlGaSe}_{2}$ [8] and $\mathrm{Ag}-\mathrm{TCM}$ (silver tricyanomethanide) [9].

A similar effect to that described in the previous paragraph, may be observed when the material is submitted to the effect of negative (expansive) pressures. In this case, the NLC effect can be defined as the decrease of the volume of the unit cell of a material under the effect of a negative pressure applied in a certain direction or as the decrease of one lattice parameter when a negative hydrostatic pressure is applied over the material. Likewise, NAC is observed when two lattice parameters decrease under the action of negative hydrostatic pressures.

In previous papers [5-6], the mechanical properties of small organic acids in the solids state, including the oxalic acid dihydrate [6], were obtained using rigorous theoretical solid-state methods based in Density Functional Theory using plane waves and pseudopotentials [10] using a high-quality setup. This material was shown to display negative Poisson ratios (NPR) and to exhibit the phenomenon of negative 
linear compressibility (NLC) for applied pressures directed along the direction of minimum Poisson ratio. One of the main motivations of these studies was to investigate the presence of negative mechanical phenomena in these materials because these effects have rarely been studied in organic compounds, pointing to a significant gap in their study. The interest is due to the large amount of potential applications of these materials, the great versatility of organic synthesis and the wide diversity of organic crystal structure types which may show these effects. The materials showing these phenomena have an enormous range of applications because they have improved material properties resulting specifically from their mechanical behavior. These properties make them appropriate in many applications as those involved in textile and automotive industries, personnel protection, biomedicine, aerospace and defense and in many commercial applications requiring filters, sieves, sensors, packaging and insulation. Negative linear compressibility, in particular, is a very relevant mechanical property which has been used for the development of ultrasensitive pressure-sensing devices, pressure driven actuators, optical telecommunication cables, artificial muscles, next-generation body armor and in biomedical uses. A complete review of the literature concerning these phenomena has been given in Ref. [6]. The main purpose of this communication is to show that, surprisingly, the oxalic acid dihydrate exhibits the important phenomenon of negative area compressibility (NAC) when submitted to external negative isotropic pressures.

\section{Methods}

The mechanical properties of the oxalic acid dihydrate [6], were obtained in a previous paper using rigorous theoretical solid-state methods based in Density Functional Theory using plane waves and pseudopotentials [10]. The PBE [11] energy-density functional supplemented with Grimme [12] empirical dispersion correction, as implemented in CASTEP [13] code, a module of the Materials Studio [14] software, was used. The computations of oxalic acid dihydrate were performed with a large kinetic cut-off of $1000 \mathrm{eV}$ and a k-mesh of $2 \times 4 \times 1$ [6]. The same methods were employed in this work with the purpose of showing that this very simple organic material, exhibits NAC. More details about the 
computational solid-state treatment of oxalic acid dihydrate used in this work may be found in the previous paper [6]. As can be seen in the previous work, the computational solid-state treatment of oxalic acid dihydrate led to a calculated crystal structure in very good agreement with the experimental one. Besides, the computed X-ray powder pattern of this material reproduced accurately its experimental counterpart [6].

\section{Results and discussion}

Table 1 reports the optimized unit cell volume and the lattice parameters of oxalic acid dihydrate submitted to different isotropic pressures. The results are also displayed in Figure 1. As can be observed in Figure 1, the $a$ and $c$ lattice parameters decrease under the application of negative pressures in the ranges from $-1.17 \mathrm{GPa}$ to $-0.12 \mathrm{GPa}$ and $-1.17 \mathrm{GPa}$ to $-0.51 \mathrm{GPa}$, respectively. Since the pressure range for the $c$ lattice parameter is fully contained in that for $a$ lattice parameter, oxalic acid dihydrate exhibits the negative area compressibility phenomenon within the range from $-1.17 \mathrm{GPa}$ to $-0.51 \mathrm{GPa}$, and the negative linear compressibility phenomenon in the rest of the pressure range from -1.17 GPa to -0.12 GPa. The computed compressibilities along $a$ and $c$ directions $\left(k_{a}=-1 / a \cdot(\partial a / \partial P)_{P}\right.$ and $k_{c}=-1 / c$. $\left.(\partial c / \partial P)_{P}\right)$ in the pressure range from $-1.0 \mathrm{GPa}$ to $-0.7 \mathrm{GPa}$ are given in Table S.1 of the Supplementary Information. As may be observed, the compressibilities in oxalic acid dihydrate are very pressure dependent. The largest magnitude of the compressibility along $a$ direction is found at $\mathrm{P}=-0.83 \mathrm{GPa}$. The calculated compressibilites at this value of the pressure are $k_{a}=-166.21 \mathrm{TPa}^{-1}$ and $k_{c}=-7.66 \mathrm{TPa}^{-1}$, respectively.

Table 2 contains a compilation of the values of the negative linear compressibilities and associated pressure ranges found in some representative materials. The materials selected, display the NLC phenomenon resulting from the most important mechanisms found so far [3], that is, ferroelastic instabilities [15-16], phonon instabilities [17-18], reverse ferroelastic phase transitions [19-20], correlated polyhedral tilts [21-27], and helical [28-31] and wine rack [32-39] structural motifs. In our case, the NLC phenomenon is associated to the layered crystal structure of oxalic acid dihydrate in which the structural 
sheets are not directly bonded but held together by means of van der Waals forces only [6]. Previous studies have shown that several organic materials [5-6] with structures closely related to that of oxalic acid dihydrate also display anomalous mechanical properties. From Table 2, it follows that the magnitude of the NLC in oxalic acid dihydrate at $\mathrm{P}=-0.83 \mathrm{GPa}$ along the [100] crystallographic direction, -166.21 $\mathrm{TPa}^{-1}$, is one of the largest found up to date.

Table 1. Unit cell volume and lattice parameters of the oxalic acid dihydrate under isotropic pressures.

\begin{tabular}{|c|c|c|c|c|c|}
\hline P(GPa) & $a(\AA)$ & $b(\AA)$ & $c(\AA)$ & $\beta(\operatorname{deg})$ & Vol. $\left(\AA^{3}\right)$ \\
\hline-1.352 & 5.5571 & 4.8172 & 11.6770 & 102.80 & 304.8140 \\
\hline-1.191 & 5.5391 & 4.7242 & 11.6290 & 102.60 & 296.9814 \\
\hline-1.093 & 5.5500 & 4.6446 & 11.6030 & 102.45 & 292.0626 \\
\hline-0.876 & 5.6880 & 4.3221 & 11.6225 & 103.36 & 277.9983 \\
\hline-0.756 & 5.7997 & 4.1001 & 11.6337 & 103.66 & 268.8119 \\
\hline-0.626 & 5.9087 & 3.8690 & 11.6523 & 104.05 & 258.4116 \\
\hline-0.498 & 5.9694 & 3.7378 & 11.6729 & 104.23 & 252.4553 \\
\hline-0.371 & 5.9908 & 3.6703 & 11.6587 & 104.25 & 248.4663 \\
\hline-0.260 & 6.0154 & 3.6115 & 11.6482 & 104.29 & 245.2256 \\
\hline-0.127 & 6.0279 & 3.5709 & 11.6274 & 104.33 & 242.4997 \\
\hline 0.007 & 6.0219 & 3.5435 & 11.6124 & 104.30 & 240.1129 \\
\hline
\end{tabular}

Figure 1. Unit cell volume and lattice parameters of the oxalic acid dihydrate under isotropic pressures.
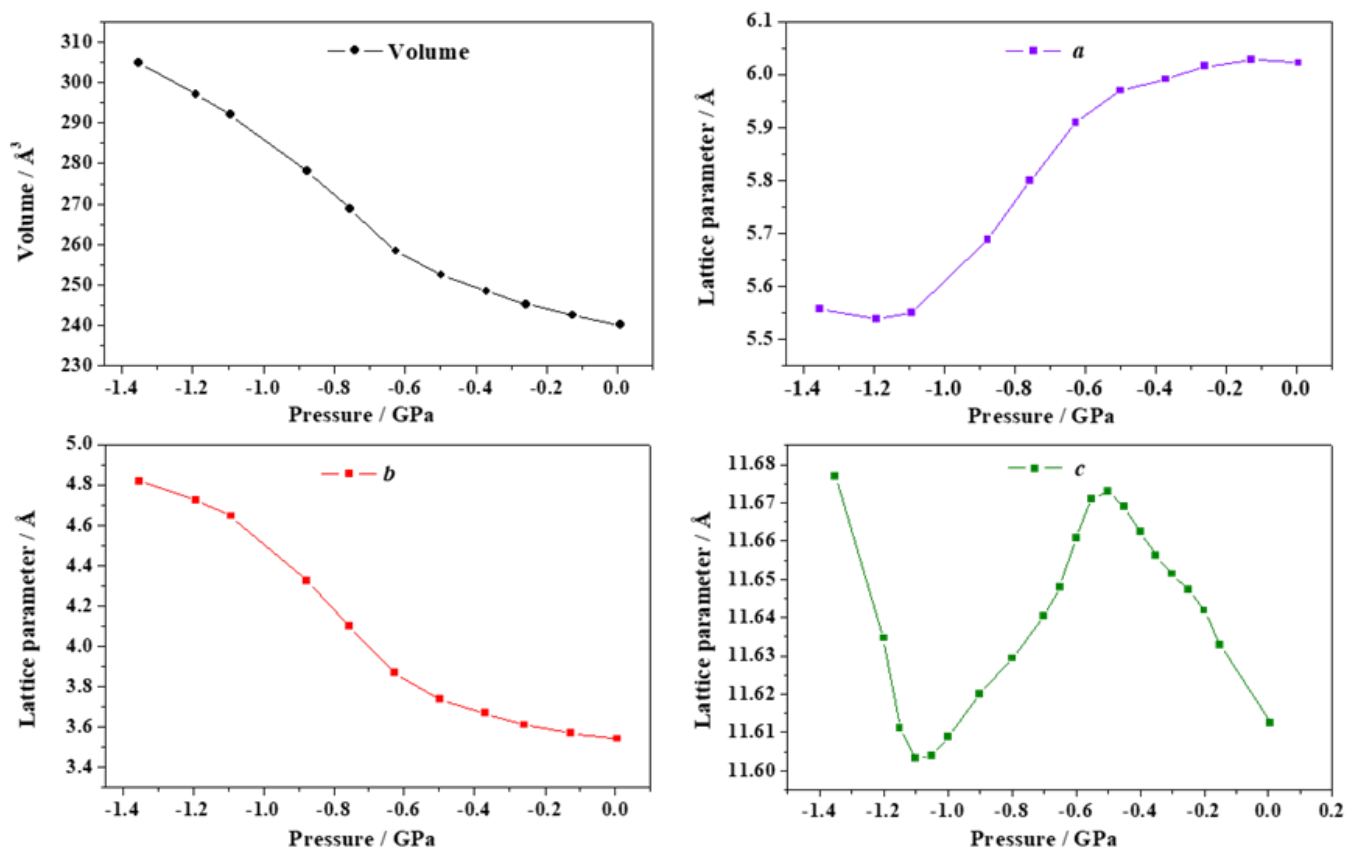
Table 2. Negative linear compressibilities and associated pressure ranges for selected NLC materials.

\begin{tabular}{|c|c|c|c|}
\hline Material & Compressibility $\left(\mathrm{TPa}^{-1}\right)$ & Pressure (GPa) & References \\
\hline $\mathrm{TeO}_{2}$ (paratellurite) & $-5.1(6)$ & 0.9 to 3.25 & {$[15-16]$} \\
\hline $\mathrm{Zn}(\mathrm{CN})_{2}$ & -2.08 & 1.52 to 5.0 & [17-18] \\
\hline $\mathrm{Pb}_{3}\left(\mathrm{PO}_{4}\right)_{2}$ & $-4.3(4)$ & 1.6 & [19-20] \\
\hline $\mathrm{BiB}_{3} \mathrm{O}_{6}$ & $\begin{array}{l}-6.7(3)[26] \\
-12.5[27]\end{array}$ & 0.0 to 5.0 & [21-22] \\
\hline GIS (gismondine) zeolites & -13.7 & 0.0 & [23-24] \\
\hline $\mathrm{CsH}_{2} \mathrm{PO}_{4}$ & -260 & 0.0 & [25-26] \\
\hline $\mathrm{BXO}_{4}(\mathrm{X}=\mathrm{P}, \mathrm{As})$ & $\begin{array}{l}\mathrm{X}=\mathrm{P}:-0.92(10) \\
\mathrm{X}=\text { As }:-1.48(15)\end{array}$ & 0.0 to 52.0 & [27] \\
\hline Te Se & Te: $-2.5(4)$ & Te: 0.0 to 14.0 & [28-29] \\
\hline le, se & Se: $-1.8(3)$ & Se: 0.0 to 3.82 & [29-30] \\
\hline $\mathrm{Zn}\left[\mathrm{Ag}(\mathrm{CN})_{2}\right]_{2}$ & $-42(5)$ & 0.0 to 1.8 & [31] \\
\hline $\mathrm{Ag}_{3}\left[\mathrm{Co}(\mathrm{CN})_{6}\right]$ & $-76(9)$ & 0.0 & [32-33] \\
\hline $\mathrm{KMn}\left[\mathrm{Ag}(\mathrm{CN})_{2}\right]_{3}$ & $-12.0(8)$ & 0.0 to 2.2 & [34] \\
\hline$\left[\mathrm{NH}_{4}\right]\left[\mathrm{Zn}(\mathrm{HCOO})_{3}\right]$ & -1.8 & 0.0 to 0.93 & [35] \\
\hline$\left[\left(\mathrm{C}_{6} \mathrm{~F}_{5} \mathrm{Au}\right)_{2}(\mu-1,4-\right.$ diisocyanobenzene $)$ & $-13(3)$ & 0.0 to 2.42 & [36] \\
\hline $\mathrm{CH}_{3} \mathrm{OH}$ & $-2.7(18)$ & 0.0 to 0.5 & [37] \\
\hline MIL - 53(Al) & -28 & 0.0 to 3.0 & \multirow{2}{*}{ [38] } \\
\hline $\mathrm{NH}_{2}-\mathrm{MIL}-53(\mathrm{Al})$ & -27 & 0.0 to 2.0 & \\
\hline $\mathrm{MIL}-140 \mathrm{~A}-\mathrm{ZrO}\left(\mathrm{O}_{2} \mathrm{C}-\mathrm{C}_{5} \mathrm{H}_{4}-\mathrm{CO}_{2}\right)$ & -3 & 0.0 & \multirow{2}{*}{ [39] } \\
\hline MIL $-140 \mathrm{C}-\mathrm{ZrO}\left(\mathrm{O}_{2} \mathrm{C}-\mathrm{C}_{12} \mathrm{H}_{8}-\mathrm{CO}_{2}\right)$ & -10 & 0.0 & \\
\hline Oxalic acid dihydrate $\left(\mathrm{C}_{2} \mathrm{O}_{4} \mathrm{H}_{2} \cdot 2 \mathrm{H}_{2} \mathrm{O}\right)$ & -166.21 & -0.83 & This work \\
\hline
\end{tabular}

The calculations reported in this paper where carried out separately with several different sets of calculation parameters (kinetic cuf-off and k-mesh), leading to increasingly more demanding computations. The convergence of the calculated crystal structures and associated energies was analyzed and the results were showed to be nearly converged with respect to the calculation parameters. The present computational treatment must be essentially reproducible and any other computational study of this material performed with sufficient level of complexity will lead to the same conclusions. Therefore, the theoretical results reported in this paper should be validated experimentally in the near future.

\section{Acknowledgement}

Supercomputer time by the CTI-CSIC center is greatly acknowledged. I want to thank Dr. Ana María Fernández for reading the manuscript and many helpful comments. 


\section{References}

[1] R. H. Baughman, S. Stafström, S. Cui and S. O. Dantas, Materials with Negative Compressibilities in One or More Dimensions, Science 279 (1998) 1522-1524. http://doi.org/10.1126/science.279.5356. 1522.

[2] J. A. Kornblatt, E. B. Sirota, H. E. King, R. H. Baughman and C. Cui, Materials with Negative Compressibilities, Science 281 (1998) 143. http://doi.org/10.1126/science.281.5374.143a.

[3] A. B. Cairns and A. L. Goodwin, Negative Linear Compressibility, Phys. Chem. Chem. Phys. 17 (2005) 20449-20465. http://doi.org/10.1039/C5CP00442J.

[4] R. S. Lakes, Negative-Poisson's-Ratio Materials: Auxetic Solids, Annu. Rev. Mater. Res. 47 (2017), 63-81. http://doi.org/10.1146/annurev-matsci-070616-124118.

[5] F. Colmenero, Anomalous mechanical behavior of the deltic, squaric and croconic cyclic oxocarbon acids, Mater. Res. Express. 6 (2019) 045610. http://doi.org/10.1088/2053-1591/aaf9d7.

[6] F. Colmenero, Mechanical Properties of Anhydrous Oxalic Acid and Oxalic Acid Dihydrate, Phys. Chem. Chem. Phys. (2019). http://doi.org/10.1039/C8CP07188H.

[7] I. Loa, K. Syassen and R. Kremer, Vibrational Properties of $\mathrm{NaV}_{2} \mathrm{O}_{5}$ under High Pressure Studied by Raman Spectroscopy, Solid State Commun. 112 (1999) 681-685. http://doi.org/10.1016/S00381098(99)00409-3.

[8] M. Y. Seyidov and R. A. Suleymanov, Negative Thermal Expansion Due to Negative Area Compressibility in TlGaSe 2 Semiconductor with Layered Crystalline Structure, J. Appl. Phys. 108 (2010) 063540. http://doi.org/10.1063/1.3486211.

[9] S. A. Hodgson, L. Adamson, S. J. Hunt, M. J. Cliffe, A. B. Cairns, A. L. Thompson, M. G. Tucker, N. P. Funnella, and A. L. Goodwin, Negative Area Compressibility in Silver(I) Tricyano-methanide, Chem. Commun. 50 (2014) 5264-5266. http://doi.org/10.1039/C3CC47032F. 
[10] M. C. Payne, M. P. Teter, D. C. Ailan, A. Arias, and J. D. Joannopoulos, Iterative minimization techniques for ab initio total-energy calculations: molecular dynamics and conjugate gradients, Rev. Mod. Phys. 64 (1992) 1045-1097. http://doi.org/10.1103/RevModPhys.64.1045.

[11] J. P. Perdew, K. Burke and M. Ernzerhof, Generalized Gradient Approximation Made Simple, Phys. Rev. Lett. 77 (1996) 3865-3868. http://doi.org/10.1103/PhysRevLett.77.3865.

[12] S. Grimme, Semiempirical GGA-type Density Functional Constructed with a Long-Range Dispersion Correction, J. Comput. Chem. 27 (2006) 1787-1799. http://doi.org/10.1002/jcc.20495.

[13] S. J. Clark, M. D. Segall, C. J. Pickard, P. J. Hasnip, M. I. J. Probert, K. Refson and M. C. Payne, First principles methods using CASTEP, Z. Kristallogr. 220 (2005) 567-570. http://doi.org/10.1524/zkri. 220.5.567.65075.

[14] MaterialsStudio, http://3dsbiovia.com/products/collaborative-science/biovia-materials-studio/, accessed Sept. 27, 2018.

[15] T. G. Worlton and R. A. Beyerlein, Structure and order parameters in the pressure-induced continuous transition in $\mathrm{TeO}_{2}$, Phys. Rev. B 12 (1975) 1899-1907. http://doi.org/10.1103/PhysRevB.12. 1899.

[16] P. S. Peercy, I. J. Fritz and G. A. Samara, Temperature and pressure dependences of the properties and phase transition in paratellurite $\left(\mathrm{TeO}_{2}\right)$ : Ultrasonic, dielectric and Raman and Brillouin scattering results, J. Phys. Chem. Solids 36 (1975) 1105-1122. http://doi.org/10.1016/00223697(75)90053-0.

[17] I. E. Collings, A. B. Cairns, A. L. Thompson, J. E. Parker, C. C. Tang, M. G. Tucker, J. Catafesta, C. Levelut, J. Haines, V. Dmitriev, P. Pattison and A. L. Goodwin, Homologous Critical Behavior in the Molecular Frameworks $\mathrm{Zn}(\mathrm{CN})_{2}$ and Cd(imidazolate $)_{2}$, J. Am. Chem. Soc. 136 (2013) 7610-7620. http://doi.org/10.1021/ja401268g.

[18] S. H. Lapidus, G. J. Halder, P. J. Chupas and K. W. Chapman, Exploiting High Pressures to Generate Porosity, Polymorphism, and Lattice Expansion in the Nonporous Molecular Framework Zn(CN) $)_{2}$, J. Am. Chem. Soc. 135 (2013) 7621-7628. http://doi.org/10.1021/ja4012707. 
[19] D. L. Decker, S. Petersen, D. Debray and M. Lambert, Pressure-induced ferroelastic phase transition in $\mathrm{Pb}_{3}\left(\mathrm{PO}_{4}\right)_{2}$ : A neutron-diffraction study, Phys. Rev. B 19 (1979) 3552-3555. http://doi.org/ 10.1103/PhysRevB.19.3552.

[20] R. J. Angel, U. Bismayer and W. G. Marshall, Local and long-range order in ferroelastic lead phosphate at high pressure, Acta Crystallogr. B 60 (2004) 1-9. http://doi.org/10.1107/ S0108768103026582.

[21] R. E. Dinnebier, B. Hinrichsen, A. Lennie and M. Jansen, High-pressure crystal structure of the non-linear optical compound $\mathrm{BiB}_{3} \mathrm{O}_{6}$ from two-dimensional powder diffraction data, Acta Crystallogr. $\mathrm{B}$ 65 (2009) 1-10. http://doi.org/10.1107/S0108768108029340.

[22] S. Haussuhl, L. Bohaty and P. Becker, Piezoelectric and elastic properties of the nonlinear optical material bismuth triborate, $\mathrm{BiB}_{3} \mathrm{O}_{6}$, Appl. Phys. A 82 (2006) 495-502. http://doi.org/10.1007/s00339005-3443-6.

[23] K. de Boer, A. Jansen and R. van Santen, Structure-stability relationships for all-silica structures, Phys. Rev. B 52 (1995) 12579-12590. http://doi.org/10.1103/PhysRevB.52.12579.

[24] F.-X. Coudert, Systematic investigation of the mechanical properties of pure silica zeolites: stiffness, anisotropy, and negative linear compressibility, Phys. Chem. Chem. Phys. 15 (2013) 1601216018. http://doi.org/10.1039/C3CP51817E.

[25] S. Prawer, T. F. Smith and T. R. Finlayson, The Room Temperature Elastic Behaviour of $\mathrm{CsH}_{2} \mathrm{PO}_{4}$, Aust. J. Phys. 38 (1985) 63-83. http://doi.org/10.1071/PH850063.

[26] Y. Kobayashi, K. Deguchi, S. Azuma, E. Suzuki, L. C. Ming, S. Endo and T. Kikegawa, Phase Transitions in $\mathrm{CsH}_{2} \mathrm{PO}_{4}$ Under High-Pressure, Ferroelectrics 285 (2003) 285, 83-89. http://doi.org/10. 1080/00150190390205924.

[27] J. Haines, C. Chateau, J. M. Leger, C. Bogicevic, S. Hull, D. D. Klug and J. S. Tse, Collapsing Cristobalitelike Structures in Silica Analogues at High Pressure, Phys. Rev. Lett. 91 (2003) 015503. http://doi.org/10.1103/PhysRevLett.91.015503. 
[28] D. R. McCann, L. Cartz, R. E. Schmunk and Y. D. Harker, Compressibility of Hexagonal Selenium by X-Ray and Neutron Diffraction, J. Appl. Phys. 43 (1972) 1432-1436. http://doi.org/10. 1063/1.1661336.

[29] H. C. Hsueh, C. C. Lee and C. W. Wang, Compression mechanisms in the anisotropically bonded elements Se and Te, Phys. Rev. B 61 (2000) 3851-3856. http://doi.org/10.1103/PhysRevB.61.3851.

[30] P. W. Bridgman, The compression of sixty-one solid substances to $25,000 \mathrm{~kg} / \mathrm{cm}^{2}$, determined by a new rapid method, Proc. Am. Acad. Arts Sci. 76 (1945) 9-24. http://www.jstor.org/stable/20023493.

[31] A. B. Cairns, J. Catafesta, C. Levelut, J. Rouquette, A. van der Lee, L. Peters, A. L. Thompson, V. Dmitriev, J. Haines and A. L. Goodwin, Giant negative linear compressibility in zinc dicyanoaurate, Nat. Mater. 12 (2013) 212-216. http://doi.org/10.1038/nmat3551.

[32] A. L. Goodwin, M. Calleja, M. J. Conterio, M. T. Dove, J. S. O. Evans, D. A. Keen, L. Peters and M. G. Tucker, Colossal Positive and Negative Thermal Expansion in the Framework Material $\mathrm{Ag}_{3}\left[\mathrm{Co}(\mathrm{CN})_{6}\right]$, Science 319 (2008) 794-797. http://doi.org/10.1126/science.1151442.

[33] A. L. Goodwin, D. A. Keen and M. G. Tucker, Large negative linear compressibility of $\mathrm{Ag}_{3}\left[\mathrm{Co}(\mathrm{CN})_{6}\right]$, Proc. Natl. Acad. Sci. U. S. A. 105 (2008) 18708-18713. http://doi.org/10.1073/ pnas.0804789105.

[34] A. B. Cairns, A. L. Thompson, M. G. Tucker, J. Haines and A. L. Goodwin, Rational Design of Materials with Extreme Negative Compressibility: Selective Soft-Mode Frustration in $\mathrm{KMn}\left[\mathrm{Ag}(\mathrm{CN})_{2}\right]_{3}$, J. Am. Chem. Soc. 134 (2012) 4454-4456. http://doi.org/10.1021/ja204908m.

[35] W. Li, M. R. Probert, M. Kosa, T. D. Bennett, T. Alagarsamy, R. P. Burwood, M. Parinello, J. A. K. Howard and A. K. Cheetham, Negative Linear Compressibility of a Metal-Organic Framework, J. Am. Chem. Soc. 134 (2012) 11940-11943. http://doi.org/10.1021/ja305196u.

[36] C. H. Woodall, C. M. Beavers, J. Christensen, L. E. Hatcher, M. Intissar, A. Parlett, S. J. Teat, C. Reber and P. R. Raithby, Hingeless Negative Linear Compression in the Mechanochromic Gold Complex $\left[\left(\mathrm{C}_{6} \mathrm{~F}_{5} \mathrm{Au}\right)_{2}(\mu-1,4-\right.$ diisocyanobenzene), Angew. Chem., Int. Ed. 52 (2013) 9691-9694. http://doi. org/10.1002/anie.201302825. 
[37] A. D. Fortes, E. Suard and K. S. Knight, Negative Linear Compressibility and Massive Anisotropic Thermal Expansion in Methanol Monohydrate, Science 331 (2011) 742-746. http://doi.org/ 10.1126/science. 1198640 .

[38] P. Serra-Crespo, A, Dikhtiarenko, E, Stavitski, J. Juan-Alcañiz, F. Kapteijn, F.-X. Coudert, J. Gascon, Experimental evidence of negative linear compressibility in the MIL-53 metal-organic framework family, CrystEngComm 17 (2015) 276-280. http://doi.org/10.1039/C4CE00436A.

[39] M. R. Ryder, M. R. Ciballeri, J.-C. Tan, Isoreticular zirconium-based metal-organic frameworks: discovering mechanical trends and elastic anomalies controlling chemical structure stability, Phys. Chem. Chem. Phys. 18 (2016) 9079-9087. http://doi.org/10.1039/C6CP00864J. 